\title{
Physiotherapy Modalities used in the Management of Chronic Low Back Pain
}

\begin{abstract}
Chronic low back pain (CLBP) is a costly and common medical problem accounting for 75-90\% of compensation costs as a result of repeated treatments, long term work absenteeism and social support-unemployment compensation. Physiotherapy treatment modalities are commonly used in the management of CLBP. Data on the management of CLBP by physiotherapists in low income countries are scarce.

A cross-sectional survey was used to investigate the management of CLBP by physiotherapists in Kwazulu-Natal (KZN). The objectives of the study were to establish: the commonly used physiotherapy modalities; reasons; and the evidence base used for their choice. Six hundred and eighty-five self-administered questionnaires were posted to all registered physiotherapists in KZN.

Of 213 returned questionnaires, 141 (20.6\%) met the inclusion criteria as they managed patients with CLBP. General exercises (30\%); spinal mobilisation (28\%); myofascial release (18\%), education (12\%) and training of local stabilisers (12\%) were the commonly used treatment modalities. Key reasons for the selection of the treatment modalities were undergraduate education received; own clinical experience and the attendance of postgraduate courses/ physiotherapy conferences.

From the reasons specified for the selection of treatment modalities, the use of written current available literature through reading of journal articles was sparsely utilized.
\end{abstract}

KEY WORDS: CHRONIC LOW BACK PAIN (CLBP); PHYSIOTHERAPY MODALITIES; PSYCHOSOCIAL FACTORS; EVIDENCE-BASED PRACTICE

\section{INTRODUCTION}

It is extensively documented that low back pain (LBP) is one of the most common and costly pandemic medical conditions affecting up to $80 \%$ of people world-wide in their lifetime (Guzman et al., 2007; Diamond and Borenstein, 2006; Cairns et al., 2006). Statistics on chronic back pain in the general population from low income countries are scarce (Omokhodion and Sanya, 2003). Thirty-thousand South African's suffer from neck and back problems on a daily basis, $10 \%$ of which will become chronic

\section{Corresponding Author:}

Vaneshveri Naidoo

Physiotherapy Department

Faculty of Health Sciences

University of the Witwatersrand

7 York Road,

Parktown

Johannesburg 2193

E-mail: Vaneshveri.naidoo@wits.ac.za.
(Van Vuuren et al., 2006). Several authors report that a small number of the population (3-10\%) will develop chronic low back pain (CLBP) (Diamond and Borenstein, 2006; Ferreira et al., 2006; Koes et al., 2006; Cassidy et al., 2005) however, it can be as much as 40\% (O’ Sullivan 2005).

The main consequences of back problems are: pain, disability, limited function (including activities of daily living) and decreased productivity (including work loss) (Kendall et al., 1997). Pain is defined as chronic if the pain persists for three months or longer (Koes et al., 2006). CLBP presents as a persistent, disabling condition and has a profound effect on quality of life (Staal et al., 2005; Kendall et al., 1997). The prognosis is less favourable and it results in considerable socioeconomic costs as a result of repeated treatments, long term work absenteeism and social support (unemployment compensation) (Koes et al., 2006; Ferreira et al., 2006).
Disability due to chronic low back pain is increasing faster than any other form of incapacity.

Physiotherapy intervention is a common form of conservative management for CLBP (Goldby et al., 2006; Cairns et al., 2006). Physiotherapy intervention consists of manual therapy (manipulation and mobilisation), exercise, advice and education as well as multidisciplinary group rehabilitation which includes the psychosocial aspect of CLBP (Guzman et al., 2007; Goldby et al., 2006; Cairns et al., 2006). The literature advocates multidisciplinary treatment, behavioural treatment (all types: operant, cognitive and respondent) and exercise therapy in the management of CLBP (van Middelkoop et al., 2011). There are also many other treatment modalities (traction, massage, tens, interferential therapy and low level laser therapy) which lack scientific evidence regarding their efficacy in the treatment of CLBP (van Middelkoop et al., 2011) 
Evidence based practice (EBP) improves the quality and appropriateness of patient care, treatment outcomes, the efficiency and effectiveness of the medical practitioner and costs involved in the management of patients (Manchikanti, 2008). It represents a shift away from the traditional practice based on clinical experience and knowledge of authorities, toward substantiated data (Bithell, 2000). Information regarding best practice/treatment is continually evolving, hence information becomes outdated and thus it is imperative to stay updated (Research Committee [Victorian Branch] of the Australian Physiotherapy Association [APA] and invited contributors, 1999).

No studies have been done in South Africa/Kwazulu-Natal (KZN) investigating the physiotherapy interventions used in the management of patients with CLBP. Thus the aim of this study was to investigate the treatment modalities which are currently being used in the management of chronic low back pain by physiotherapists in KZN.

\section{METHODOLOGY}

This quantitative descriptive cross sectional study was conducted using a self-administered questionnaire with the aim as stated above. Ethical clearance was granted by the Witwatersrand University Human Research Ethics Committee (clearance number: M070908). All (685) practicing physiotherapists in KZN registered with the Health Professions Council of South Africa involved in the management of chronic low back pain were includedinthe study.Aquestionnaire was developed for this study with the aid of current literature (Guzman et al., 2007; Taylor et al., 2007; Goldby et al., 2006; Ferreira et al., 2006; Kaapa et al., 2006; Koes et al., 2006; Moseley et al., 2004) and a group of academic and clinical (all of whom are Orthopaedic Manipulative Therapy (OMT) trained and OMT course lecturers) experts involved with the management of CLBP. The questionnaire contained the following sections: - Biographical information (age; gender; qualifications obtained; number of years qualified; type of employment; area of practice and professional body membership); Management of CLBP (involved in the management of patients with CLBP; statistics on the number of CLBP patients treated; modalities used to manage
CLBP; three prioritised modalities in CLBP management; postgraduate courses attended; the cause of CLBP; pain mechanism of chronic pain and psychosocial aspects of CLBP) and questions about: the number of journal articles read; the source of the articles; the ability to critique articles; characteristics of a good article and recognition of levels of evidence (Sackett et al., 1998).

The test-retest reliability of the questionnaire was established in the pilot study on ten physiotherapists. There

\section{Commonly used Treatment Modalities}

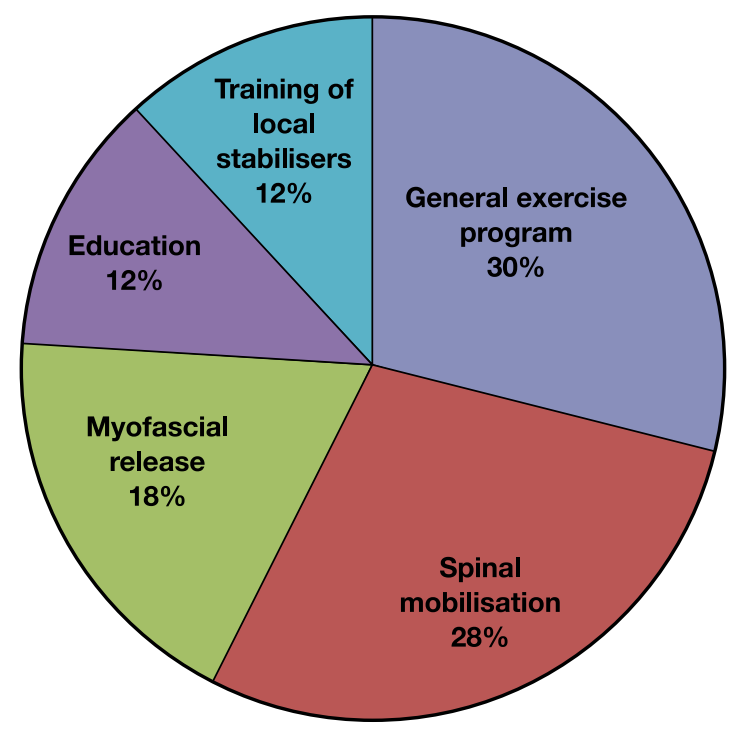

Figure 1: Commonly used treatment modalities in the management of CLBP $(n=141)$

Table 1: Prioritised treatment modalities used in the management of CLBP

\begin{tabular}{|l|l|l|l|}
\hline $\begin{array}{l}\text { Mreatment } \\
\text { Modalities }\end{array}$ & $\begin{array}{l}\mathbf{1}^{\text {st }} \text { prioritised } \\
\text { modality } \\
\mathbf{( n = 1 2 8 )} \\
\mathbf{n}(\%)\end{array}$ & $\begin{array}{l}\mathbf{2}^{\text {nd }} \text { prioritised } \\
\text { modality } \\
\mathbf{( n = 1 3 1 )} \\
\mathbf{n}(\%)\end{array}$ & $\begin{array}{l}\mathbf{3}^{\text {rd }} \text { prioritised } \\
\text { modality } \\
\text { (n=129) } \\
\mathbf{n}(\%)\end{array}$ \\
\hline Spinal mobilisation & $40(31)$ & $31(24)$ & $13(10)$ \\
\hline Myofascial release & $17(13)$ & $25(19)$ & $19(15)$ \\
\hline Education & $17(13)$ & $5(4)$ & $2(2)$ \\
\hline Training local stablisers & $12(9)$ & $14(11)$ & $17(12)$ \\
\hline General Exercises & $7(6)$ & $12(9)$ & $29(22)$ \\
\hline Ergonomics/Kinetic Handling & $5(4)$ & $8(6)$ & $12(9)$ \\
\hline Heat/ice/strapping & $9(7)$ & $5(4)$ & $9(7)$ \\
\hline Dry needling & $1(1)$ & $5(4)$ & - \\
\hline Interferential therapy & $2(2)$ & $3(2)$ & $6(5)$ \\
\hline Ultrasound therapy & $1(1)$ & $2(1)$ & $3(2)$ \\
\hline Shortwave therapy & $1(1)$ & - & $1(1)$ \\
\hline Cognitive \& Behavioral therapy & $5(4)$ & $3(2)$ & $4(3)$ \\
\hline Motor control exercises & $3(2)$ & $3(2)$ & $2(2)$ \\
\hline Stretching exercises & $1(1)$ & $4(3)$ & $4(3)$ \\
\hline Traction & - & $3(2)$ & $1(1)$ \\
\hline Neural tissue mobilisation & - & $4(3)$ & $4(3)$ \\
\hline Massage & $7(6)$ & $4(3)$ & \\
\hline
\end{tabular}




\section{Knowledge of the pain mechanism involved in CLBP}

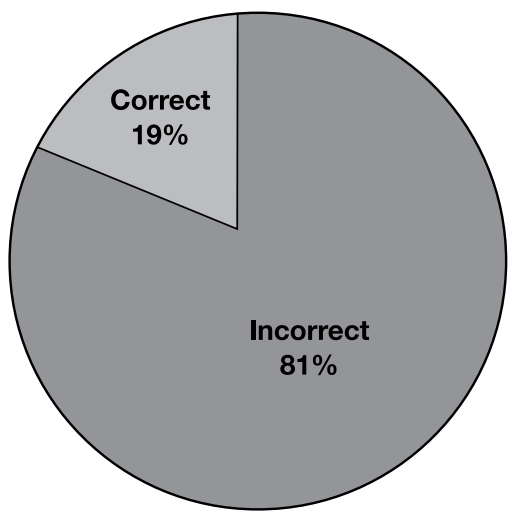

Figure 2: Knowledge of the pain mechanism involved in CLBP $(n=141)$

Table 2: The most frequently selected Reasons for the chosen modalities $(n=141)$

\begin{tabular}{|c|c|c|}
\hline Modality & Reason & Number / (\%) \\
\hline \multirow{4}{*}{$\begin{array}{l}\text { Spinal } \\
\text { mobilisation }\end{array}$} & Undergraduate education & $65(46)$ \\
\hline & $\begin{array}{l}\text { Clinical experience proves effectiveness } \\
\text { of the modality }\end{array}$ & $25(18)$ \\
\hline & Pathophysiological basis & $13(9)$ \\
\hline & $\begin{array}{l}\text { Postgraduate courses / } \\
\text { Physiotherapy conferences }\end{array}$ & $12(9)$ \\
\hline \multirow{4}{*}{$\begin{array}{l}\text { General Exercise } \\
\text { Program }\end{array}$} & Undergraduate education & $42(30)$ \\
\hline & $\begin{array}{l}\text { Clinical experience proves effectiveness } \\
\text { of the modality }\end{array}$ & $22(16)$ \\
\hline & Motivates the patient & $10(7)$ \\
\hline & $\begin{array}{l}\text { Postgraduate courses / } \\
\text { Physiotherapy conferences }\end{array}$ & $8(6)$ \\
\hline \multirow[t]{4}{*}{ Myofascial release } & Undergraduate education & $35(25)$ \\
\hline & $\begin{array}{l}\text { Clinical experience proves effectiveness } \\
\text { of the modality }\end{array}$ & $35(25)$ \\
\hline & $\begin{array}{l}\text { Postgraduate courses / } \\
\text { Physiotherapy conferences }\end{array}$ & $29(21)$ \\
\hline & Pathophysiological basis & $21(15)$ \\
\hline \multirow[t]{4}{*}{ Education } & Undergraduate education & $49(35)$ \\
\hline & Motivates the patient & $29(21)$ \\
\hline & $\begin{array}{l}\text { Clinical experience proves effectiveness } \\
\text { of the modality }\end{array}$ & $17(12)$ \\
\hline & $\begin{array}{l}\text { Postgraduate courses / } \\
\text { Physiotherapy conferences }\end{array}$ & $16(11)$ \\
\hline \multirow{4}{*}{$\begin{array}{l}\text { Training local } \\
\text { stabilisers }\end{array}$} & Undergraduate education & $38(27)$ \\
\hline & $\begin{array}{l}\text { Postgraduate courses / } \\
\text { Physiotherapy conferences }\end{array}$ & $26(18)$ \\
\hline & $\begin{array}{l}\text { Clinical experience proves effectiveness } \\
\text { of the modality }\end{array}$ & $23(16)$ \\
\hline & Evidenced based literature & $15(11)$ \\
\hline
\end{tabular}

were no differences in the answers given between the first round and second round that was conducted one week later. The questionnaire and information sheet were both posted and emailed to the subjects. Descriptive statistics were used to present the data as frequencies and percentages

\section{RESULTS}

A total of 685 questionnaires were distributed, $213(31.1 \%)$ were returned. One hundred and forty one $(20.6 \%)$ physiotherapists were involved in the management of chronic low back pain. Eighty-four percent were females, aged between 20-30 years (49\%). The majority had post qualification experience of between three and ten years (87\%). Six percent of the study sample had post graduate qualifications and sixtyfive percent of the study sample was employed in private practice.

Twenty-eight percent of the study sample treated between 11 and 20 patients with CLBP per month, followed closely by $25 \%$ of the sample who treated more than 20 patients per month.

A general exercise program $(30 \%)$ and spinal mobilisation (28\%) were the most commonly used physiotherapy treatment modalities for CLBP, followed by myofascial release (MFR) (18\%), education $(12 \%)$ and training of local stabilisers (12\%), (see Figure 1).

The first and second prioritised treatment modalities happened to be the same (spinal mobilisation) followed thirdly by general exercise. These results are illustrated in Table 1. The most frequently selected reasons for the chosen modalities included undergraduate education and clinical experience, (see Table 2).

Seventy-three percent of the respondents were unaware that CLBP stemmed from simple mechanical backache rather than serious spinal pathology or nerve root pain. Eighty-one percent of the study sample did not recognise the pain mechanism (central sensitisation) associated with chronic pain compared to nociception, peripheral sensitisation, central phenomenon and general sensitisation, (see figure 2)

Ninety-four percent of the study sample assessed for yellow flags in patients with CLBP, but none of the respondents were able to identify all these psychosocial factors. They only identified between three and five out of 
nine factors that should be investigated.

Forty-seven percent read between 1-5 articles per year while $16 \%$ percent of the study sample did not read any articles. Forty-two percent critiqued the journal articles they read. When critically reviewing an article only three of the accepted characteristics of a good article could be identified by the study sample. No more than $9 \%$ was able to correctly identify the levels of evidence of journal articles.

\section{DISCUSSION}

Spinal mobilisation was the overwhelming modality of choice by the study sample. Chiradejnant et al. (2003)'s study confirmed that spinal mobilisation assists with pain relief and improves mobility of the spine and that mobilisation of the lumbar spine has an immediate effect in relieving low back pain (Bokarius and Bokarius, 2010). Hence probably a reason why therapists would choose a modality which produces an immediate positive effect, as patients expect to obtain some pain relief after having received treatment (Goosens et al., 2005). Despite this treatment modality finding favour among the study sample, the efficacy of spinal mobilisation in the treatment of CLBP is unpersuasive and many studies have found that spinal mobilisation does not produce significant reductions in pain and disability (Rubenstein et al., 2011; Mohensi-Bandpei et al., 2006; Bronfort et al., 2004; Avery and O'Driscoll, 2004). Bokarius and Bokarius, 2010 also report a high recurrence rate of back pain one year post treatment following spinal mobilization.

A general exercise program (30\%) was also commonly used to manage patients with CLBP. Exercises (irrespective of the type of exercise) are most efficacious in the management of patients with CLBP (Lewis et al., 2008). There is increasing evidence proving that rehabilitation which involves exercise therapy is the most effective in reducing pain, disability and the recurrence of LBP (Smith and Grimmer-Sommers 2010; Taylor et al., 2007; Ferreira et al., 2006).

Education about CLBP and training of the local stabiliser muscles was used by $12 \%$ of the physiotherapists in this study. Educating patients as well as training of the local stabiliser muscles is often time consuming and requires sound knowledge of the educator/therapist (De Jong et al., 2005; Lorimar et al., 2004). Training of local stabilisers also requires a high level of skill of the therapist (O' Sullivan, 2000). Education concerning CLBP is effective in the short term only regarding pain relief; return to work and function in general, but it has the ability to change attitudes, beliefs and behaviour which is integral in the management of chronic pain (de Jong et al., 2005; Moseley et al., 2004;).

Eighteen percent of the study sample used myofascial release in the management of CLBP. Evidence regarding MFR in CLBP is lacking; however the beneficial effects of MFR are seen in both pelvic asymmetry (Barnes et al., 2011) and fibromyalgia (Castro-Sanchez et al., 2011).

The most popular reasons cited for the choice of treatment modality chosen were: undergraduate education, clinical experience, and knowledge gained through postgraduate courses / physiotherapy conferences. Undergraduate institutions play an important role regarding the attitudes of graduates with regard to evidence based practice (EBP), (Research Committee [Victorian Branch] of the APA and invited contributors, 1999). Furthermore, Louw and Morris (2010) state that through EBP educational requirements for physiotherapists regarding the management of $\mathrm{LBP}$, and hence CLBP as well, can be assessed, consequently contributing to the vital impact of undergraduate education in patient management.

Chronic pain and disability due to back pain is associated with psycho-social factors (Bokarius VA and Bokarius V, 2010; Kaapa et al., 2006; Koes et al., 2006). Ninety-four percent of the study sample assessed the psychosocial aspects of CLBP, but none of the respondents were cognisant of all the psycho-social factors that need to be assessed. The cause of CLBP is "multifactorial" in nature (Kaapa et al., 2006; O' Sullivan, 2005) and needs to be considered within a "biopsychosocial framework" (O' Sullivan, 2005). The biopsychosocial model of chronic low back pain and disability comprises of: "pain; attitudes and beliefs; psychological distress; illness behaviour and social environment" (Waddell, 1999). The interaction of these factors contributes to the CLBP disorder and disability (O' Sullivan, 2005; Waddell, 1999). For effective treatment of this disorder, the main "driving mechanism" of the pain must be identified. If psychosocial factors are disregarded, chronic pain and disability perpetuates, thereby forfeiting 'reasonable' quality of life. This study sample treated a considerable number of patients with CLBP per month (about 20 patients per month); therefore it is imperative that physiotherapists are cognisant of all psychosocial factors or 'yellow flags' to ensure the successful management of these patients.

Physiotherapists in this study did not use evidence from literature when selecting treatment modalities for the management of CLBP. Forty-seven percent read between one and five articles per year, whilst $16 \%$ did not read any articles. Berger (2007) is of the opinion that the available evidence provides little guidance to clinicians who need to decide which interventions to implement for chronic low back pain. Conversely, Koes et al. (2006) presented clear guidelines regarding the management of patients with CLBP which could be used by physiotherapists. Interpretation of results in journal articles can at times be difficult if one is not well versed with the statistics that were used, something that was alluded to by the respondents in this study. The language used in articles is sometimes intricate and can be a deterrent to reading of articles. This could be why physiotherapists do not use the current available written evidence in clinical practice (Smith and GrimmerSomers 2010), although they may get information on EBP from CPD courses and congresses.

Eighty-seven percent of the respondents were unable to correctly identify the levels of evidence of journal articles. Evaluating evidence requires critical appraisal skills (Research Committee of the Victorian Branch of the APA and invited contributors) and if lacking it would be difficult to recognise and implement evidence. Forty-two percent of the study sample reported that they critique articles that they read. Most respondents were only able to identify between one and five characteristics which constitutes a good journal article, out of the 10 correct responses. Respondents were thus unable to discern between good and poor quality journal articles. 


\section{CONCLUSION}

The commonly used modalities in the management of CLBP were general exercises; spinal mobilisation; myofascial release; education and training of the local stabiliser muscles.

The reasons cited for the choice of modality selected included undergraduate education received, the attendance of postgraduate courses physiotherapy conferences and clinical experience. From the reasons specified, the use of written current available literature through reading of journal articles was sparsely utilized.

\section{REFERENCES}

Avery S and O'Driscoll ML. 2004 Randomised controlled trials on the efficacy of spinal manipulative therapy in the treatment of low back pain. Physical Therapy Reviews 9 (3): 146 - 152

Barnes MF, Gronlund RT, Little MF, Personius WJ. 2011 Efficacy study of the effect of a myofascial release treatment technique on obtaining pelvic symmetry links. The Cochrane Central Register of Controlled Trials (CENTRAL) 3: CN00209283

Berger P. 2007 Perspectives on Physiotherapy Guidelines for Chronic Low back Pain. South African Journal of Physiotherapy 63 (3): 15-21

Bithell C. 2000 Evidence-based physiotherapy. Physiotherapy 86 (2): 58-60

Bokarius AV, Bokarius V.2010 Evidence-Based Review of Manual Therapy Efficacy in Treatment of Chronic Musculoskeletal Pain. Pain Practice 10(5): 451-458

Bronfort G, Haas M, Evans RL, et al. 2004 Efficacy of spinal Manipulation and mobilization for low back pain and neck pain: a systematic review and best evidence synthesis. Spine Journal 4 (3): $335-56$

Cairns MC, Foster NE, Wright C. 2006 Randomized controlled trial of specific spinal stabilization exercises and conventional physiotherapy for recurrent low back pain. Spine 31 (19): E670-81

Cassidy JD, Cote P, Carrel LJ, Kristman V. 2005 Incidence and course of low back pain episodes in the general population. Spine 30 (24): 2817-2823

Castro-Sanchez AM, Mataran-Penarrocha GA, Granero-Molina J, Aguilera-Manrique G, QuesadaRubio JM, Moreno-Lorenzo C. 2011 Benefits of Massage-Myofascial Release Therapy on Pain, Anxiety, Quality of Sleep, Depression, and Quality of Life in Patients with Fibromyalgia. Evidence-Based Complementary and Alternative Medicine: 1-9

Chiradeinant A, Maher CG, Latimer J, Stepkovitch N. 2003 Efficacy of "therapist-selected" versus "randomly-selected" mobilization techniques for the treatment of low back pain: a randomized controlled trial. Australian Journal of Physiotherapy 49 (4): 233-241

Clarke JA, van Tulder MW, Blomberg SE, de Wet HCW, van der Heijden GJ, Bronfort G, Bouter LM. 2010 traction for low- back pain with or without sciatica. Cochrane Database Systematic Reviews: CD003010

de Jong JR, Vlaeyen JWS, Onghena P, Goosens MEJB, Geilen M, Mulder H. 2005 Fear of movement / $(\mathrm{Re})$ injury in chronic low back pain Education or exposure in vivo as mediator to fear reduction? Clinical Journal of pain 21 (1): 9-17

Diamond S, Borenstein D. 2006 Chronic low back pain in the working- age adult. Best Practice Research in Clinical Rheumatology 20 (4): 707-720

Ferreira PH, Ferreira ML, Maher CG, et al. 2006 Specific stabilization exercise for spinal and pelvic pain: A systematic review. Australian Journal of Physiotherapy 52: 77-88

Goldby LJ, Moore AP, Doust J, et al. 2006 A randomized controlled trial investigating the efficacy of musculoskeletal physiotherapy on chronic low back disorder. Spine 31 (10): 1083-93

Goosens, Marielle, Vlaeyen, Johan, Hidding, Alita Kole-Snijders, Ank, Evers, Silvia. 2005 Treatment expectancy affects the outcome of cognitivebehavioral interventions in chronic pain. Clinical Journal of pain 21 (1): 18-26

Guzman J, Esmail R, Karjalainen K, et al. 2007 Multidisciplinary bio-psyco-social rehabilitation for chronic low back pain. Cochrane Database Systematic Reviews 18 (3): CD000963

Kaapa EH; Frantsi K, Sarna S, et al. 2006 Multidisciplinary group rehabilitation versus Individual physiotherapy for chronic nonspecific low back pain. A randomized controlled trial. Spine 31 (4): 371-376

Kendall NAS, Linton SJ, Main CJ. 1997 Guide to assessing psychosocial yellow flags in acute low back pain: Risk factors for long term disability and work loss. Accidental Rehabilitation and Compensation Insurance Corporation of New Zealand and the National Health Committee, New Zealand. www.nzgg.org.nz/library/g1 complete/backpain2/full_text.cfm

Koes BW, van Tulder MW, Thomas S. 2006 Diagnosis and treatment of low back pain (Clinical Review). British Medical Journal 332: 1430-1434

Lewis A, Morris ME, Walsh C. 2008 Are physiotherapy exercises effective in reducing chronic low back pain? Physical Therapy Reviews 13 (1): $37-44$

Lorimer MG, Nicholas MK, Hodges PW. 2004 A Randomised Controlled Trial of Intensive Neurophysiology Education in Chronic Low Back Pain. The Clinical Journal of pain 20 (5): 324-330

Louw QA, Morris LD. 2010 Physiotherapeutic acute low back pain interventions in the private health sector of the Cape Metropole, South Africa. SA Journal of Physiotherapy 66 (3): 8-14

Manchikanti L. 2008 Evidence-based medicine, systematic reviews, and guidelines in interventional pain management, part 1: introduction and general considerations. Pain Physicians 11 (2) 161-186

Mohseni-Badpei MA, Critchley J, Staunton T, Richardson B. 2006 A prospective randomized controlled trial of spinal manipulation and ultrasound in the treatment of chronic low back pain. Physiotherapy 92: 34-42

Moseley GL, Nicholas MC, Hodges PW. 2004 A Randomised controlled trial of intensive neurophysiology education in chronic low back pain. Clinical Journal of pain 20 (5): 324-330

Omokhodion FO, Sanya AO. 2003 Risk factors for low back pain among office workers in Ibadan, Southwest Nigeria. Occupational Medicine 53: 287-289

O' Sullivan P. 2005 Diagnosis and classification of chronic low back pain disorders: Maladaptive movement and motor control impairments as underlying mechanism. Manual therapy 10 : 242-255

O' Sullivan PB. 2000 Lumbar segmental 'instability': clinical presentation and specific stabilizing exercise management. Manual Therapy 5 (1): 2-12

Research Committee (Victorian Branch) of the Australian Physiotherapy Association and invited contributors. 1999 Evidence-based practice. Australian Journal of Physiotherapy 45: 167-171

Rubenstien SM, van Middelkoop M, Assendelft W, de Boer MR, van Tulder MW. Spinal manipulative therapy for chronic low-back pain. Cochrane Database Systematic Reviews: CD008112

Sackett D, Richardson W, Rosenberg W, Haynes R. 1998 Evidence-Based Medicine - How to Practice and Teach EBM. Edinburgh: Churchill Livingston

Smith C, Grimmer-Somers K. 2010 The treatment effect of exercise programmes for chronic low back pain. Journal of Evaluation in Clinical Practice 16: 484-491

Staal JB, Rainville J, Frits J, et al. 2005 Physical exercise interventions to improve disability and return to work in low back pain: Current insights and opportunities for improvement. Journal of occupational Rehabilitation 15 (4): 491-505

Taylor NF, Dodd KJ, Shields N, et al. 2007 Therapeutic Exercise in physiotherapy practice is beneficial: A summary of systematic reviews 2002 - 2005. Australian Journal of Physiotherapy 53: 7-16

van Middelkoop M, Rubenstien SM, Kuijpers T, Verhagen AP, Ostelo R, Koes BW, van Tulder MW. 2011 A systematic review on the effectiveness of physical and rehabilitation interventions for chronic non-specific low back pain.2011 European Spine Journal 20: 19-39

Van Vuuren B, van Heerden HJ, Bekker PJ, Zinzen E, Meeusen R. 2006 Fear-avoidance beliefs and pain coping strategies in relation to lower back problems in a South African steel industry. European Journal of pain 10 (3): 233-239

Waddell G. 1999 The Back Pain Revolution. London. Churchill-Livingstone 